\title{
Carcinoma Espinocelular de Reto: Relato de Caso
}

\author{
Squamous Cell Carcinoma of the Rectum: A Case Report \\ JULIANAMAGALHÃES LOPES ${ }^{1}$; JULIANABARRETO SALEM ${ }^{1}$; FLÁVIABALSAMO ${ }^{2}$; HERNÁNAUGUSTO \\ CENTURIÓN SOBRAL ${ }^{1}$; LETÍCIA SARMANHO'; GALDINO JOSÉ SITONIOFORMIGA ${ }^{3}$ \\ ${ }^{1}$ Ex- residentes do Serviço de Coloproctologia do Hospital Heliópolis, SP; ${ }^{2}$ Assistente do Serviço de \\ Coloproctologia do Hospital Heliópolis- São Paulo, SP, TSBCP; ${ }^{3}$ Chefe do Serviço de Coloproctologia do Hospital \\ Heliópolis, SP, TSBCP.
}

LOPES JML; SALEM JB; BALSAMO F; SOBRAL HAC; SARMANHO L; FORMIGA GJS. Carcinoma Espinocelular de Reto: Relato de Caso. Rev bras Coloproct, 2010;30(1): 079-082.

RESUMO: O Carcinoma Espinocelular de Reto é entidade extremamente rara e seu comportamento biológico permanece desconhecido. $O$ tratamento pode variar entre radio e quimioterapia isoladamente ou complementar ao tratamento cirúrgico. Relatamos caso de carcinoma espinocelular de reto superior, tratado com radio e quimioterapia, com regressão total da lesão.

Descritores: Carcinoma retal, carcinoma de células escamosas do reto, reto, câncer, tratamento.

\section{INTRODUÇÃO}

O Carcinoma Espinocelular (CEC) de reto é extremamente raro, sendo a incidência estimada entre 0,002 e $1 \%$ dos tumores malignos colorretais ${ }^{1}$. Sua patogênese não está esclarecida e há algumas teorias para explicar sua etiologia ${ }^{2}$.

As manifestações clínicas são semelhantes às do adenocarcinoma, assim como o prognóstico, principalmente quando os linfonodos são negativos. Quando estes estão comprometidos, o prognóstico é pior ${ }^{3}$.

A cirurgia como tratamento e a radio e quimioterapia primárias ou adjuvante não estão bem definidas devido a raridade desta entidade ${ }^{4,5}$.

O objetivo deste estudo é relatar um caso de CEC de reto superior tratado exclusivamente com radio e quimioterapia e apresentar revisão da literatura.

\section{RELATO DO CASO}

M.H., 50 anos, masculino, há quatro meses com alteração do hábito intestinal de uma vez ao dia para uma vez a cada dois ou três dias, associada a fezes em cíbalos, puxo, tenesmo e hematoquezia. Ao exame proctológico verificou-se lesão vegetante, friável e sangrante de reto localizada em parede ântero-lateral direita, entre 10 e $13 \mathrm{~cm}$ da borda anal, pérvia. $\mathrm{O}$ estudo colonoscópico revelou-se normal até o ceco e confirmou a lesão previamente descrita, submetida à biópsia (Figura 1).

A anatomia patológica demonstrou tratar-se de carcinoma espinocelular pouco diferenciado, exame este repetido e confirmado (Figura 2).

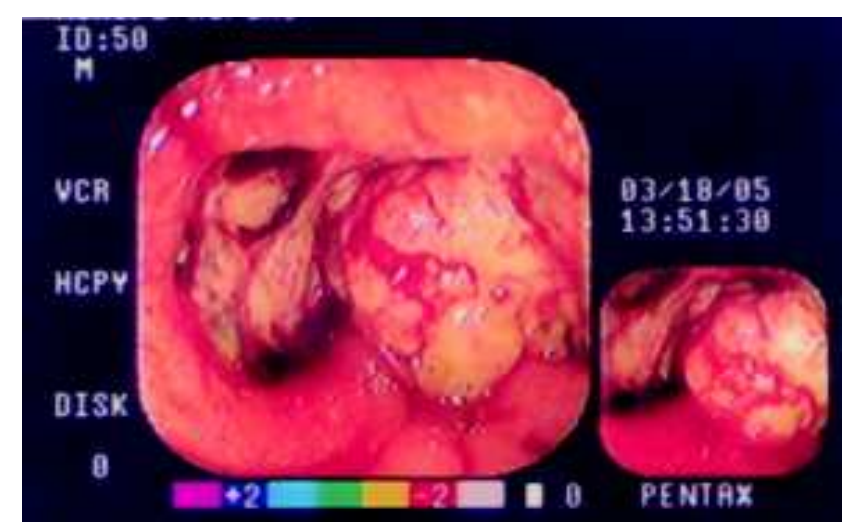

Figura 1 - Lesão vegetante de reto.

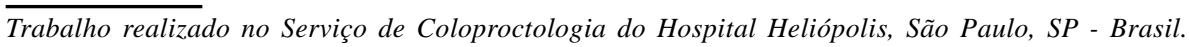

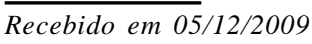

Aceito para publicação em 27/12/2009 
A tomografia computadorizada de abdome e pelve apresentou espessamento parietal do reto associado a borramento da gordura perivisceral (Figura 3) e lesões hipodensas hepáticas em ambos os lobos, sugestivas de cistos. A radiografia de tórax mostrou-se dentro da normalidade.

$\mathrm{O}$ paciente foi submetido à radioterapia com 5400 cGy e três ciclos de quimioterapia com paclitaxel $(200 \mathrm{mg}$ ) e cisplatina (100 mg). Após oito semanas, foi realizada retossigmoidoscopia flexível até $25 \mathrm{~cm}$ da borda anal que demonstrou apenas fibrose anelar localizada a $10 \mathrm{~cm}$ da mesma. (Figura 4)

A biópsia seguida de estudo histo-patológico revelou retite crônica inespecífica, resultado repetido em biópsias após 20 e 32 semanas do tratamento. O estadiamento por tomografia após tratamento radioterápico confirmou remissão do espessamento retal. (Figura 5) Paciente mantém-se em seguimento oncológico regular e está assintomático há 1 ano.

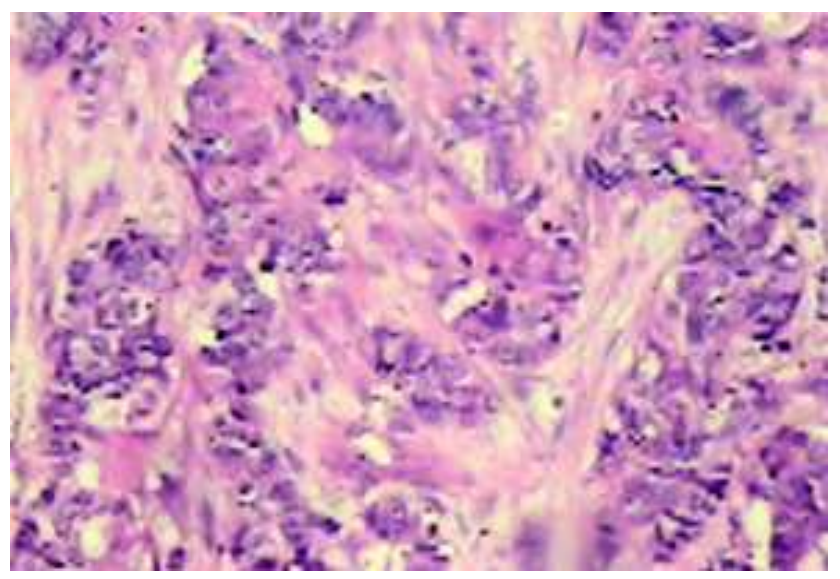

Figura 2 - Carcinoma espinocelular do reto-histologia.

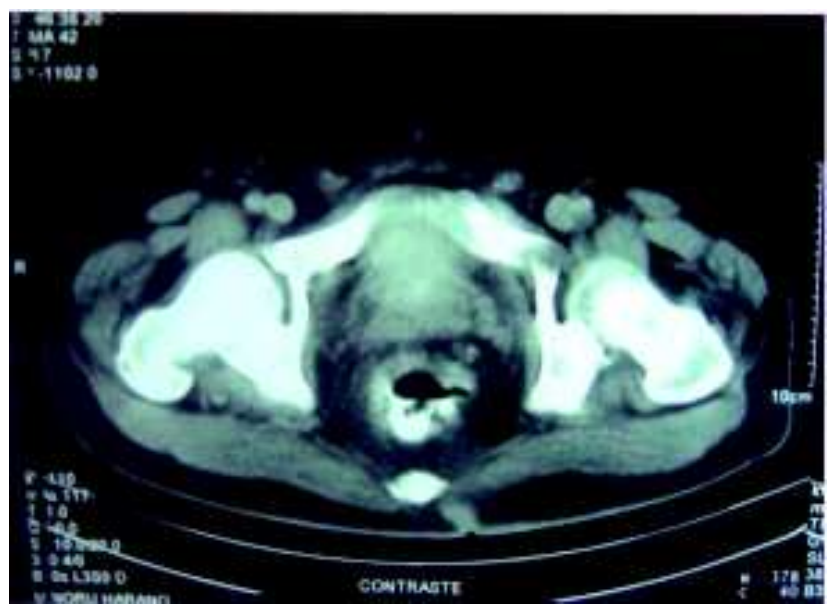

Figura 3 - Espessamento parietal do reto.

\section{DISCUSSÃO}

O carcinoma espinocelular de reto é um tumor extremamente raro ${ }^{4}$. $\mathrm{O}$ primeiro caso de CEC no reto foi descrito por Raiford em $1933^{5}$. Entre os CEC colorretais, o reto e o cólon ascendente são os locais mais frequentemente envolvidos ${ }^{4}$.

A causa deste tipo de tumor permanece desconhecida, porém algumas teorias foram propostas. Sua etiologia pode estar relacionada ao aumento da proliferação de células basais após agressão da mucosa. Estas, ao invés de se diferenciarem em epitélio glandular, poderiam sofrer diferenciação aberrante para epitélio escamoso, podendo também malignizar-se ${ }^{2,5}$.

O CEC colorretal também pode surgir de uma metaplasia escamosa secundária à agressão crônica (radiação, colite ulcerativa, infecção por HPV ou esquistossoma), como ocorre com o CEC de pulmão. Outra hipótese é que o tumor pode originar-se de um

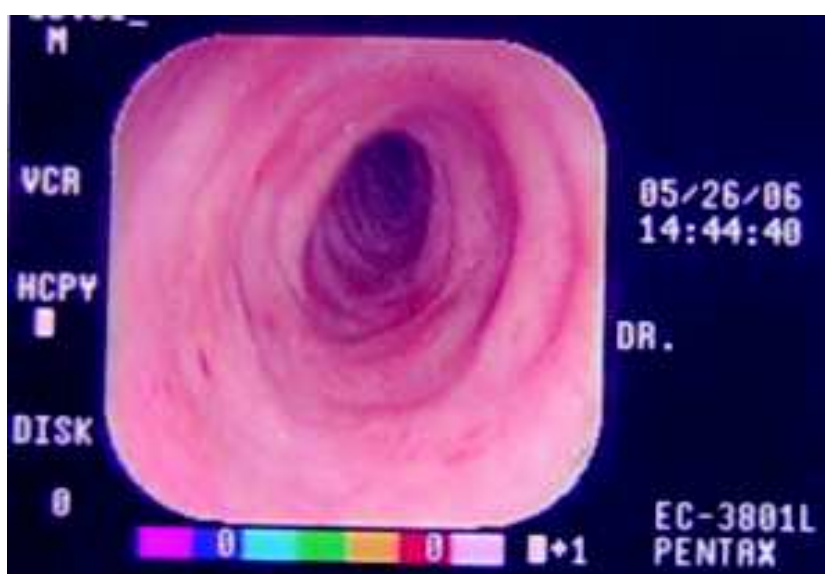

Figura 4 - aspecto endoscópico após tratamento.

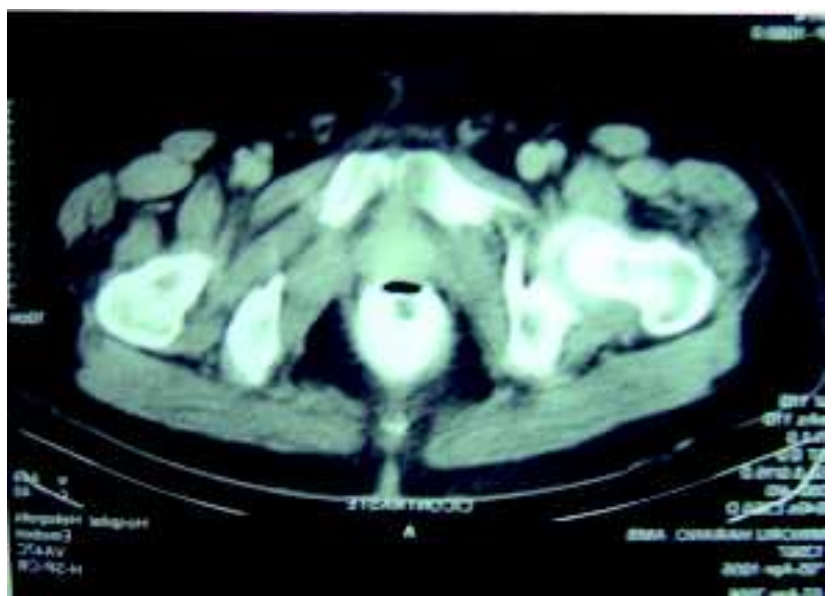

Figura 5 - aspecto tomográfico após tratamento. 
nicho de células embrionárias confinadas ou não ao ectoderma, constituindo uma ectopia após a embriogênese ${ }^{2,5}$.

A sintomatologia é semelhante a do adenocarcinoma de reto: puxo, tenesmo e hematoquezia, como evidenciado no caso relatado, podendo iniciar-se em poucas semanas ou até meses ${ }^{5}$.

A biópsia incisional ou excisional seguida de estudo anátomo-patológico é o único meio de diferenciar o carcinoma espinocelular do adenocarcinoma ${ }^{5}$. No caso descrito, após identificação da lesão retal em exame proctológico, foi realizada biópsia com suspeita de adenocarcinoma. A anatomia patológica diagnosticou CEC de reto, sendo a lâmina encaminhada para revisão, confirmando o achado.

O prognóstico é semelhante ao do adenocarcinoma nos estádios I e II. Quando há linfonodos comprometidos, o prognóstico é pior do que o esperado para o adenocarcinoma no mesmo estádio ${ }^{3}$. Parece ser mais invasivo localmente e envolver mais frequentemente os linfonodos regionais que $o$ adenocarcinoma. Os locais mais comuns de metástases à distância são o fígado e o pulmão ${ }^{6}$. Até então, não foram detectadas lesões a distância no nosso caso.

A cirurgia tem sido o tratamento principal na maioria dos casos de CEC colorretal descritos, porém com base nos conhecimentos existentes de CEC de canal anal ${ }^{7}$, foi optado por tratamento com quimio e radioterapia neste caso, ocorrendo regressão total do tumor. Como o CEC de canal anal é radiossensível, há possibilidade de radioterapia e/ou quimioterapia como tratamento exclusivo, adjuvante ou neoadjuvante ${ }^{8}$. Na literatura revisada, foram encontrados poucos casos com regressão total da lesão após radio e quimioterapia apenas e em nenhum relato foram utilizadas as drogas paclitaxel e cisplatina.

Os resultados do tratamento são difíceis de serem analisados pela raridade do tumor, o que não afasta a possibilidade de tratamento curativo com radio e quimioterapia exclusivas ${ }^{5,9}$. Por outro lado, o seguimento oncológico regular permite a mudança de condução do caso, optando-se por ressecção cirúrgica em caso de recrudescimento da doença. Para esta conclusão será necessário maior seguimento deste paciente e maior número de casos.

ABSTRACT: Squamous cell carcinoma of the rectum is a extremely rare neoplasm and its biological behavior remains unknown. Treatment varies from surgery with and without adjuvant therapy to chemotherapy and radiotherapy alone. We present a patient with squamous cell carcinoma of the superior rectum who underwent chemo and radiotherapy exclusively, with total regression of the tumor.

Key words: Rectal carcinoma, rectal squamous cell carcinoma, rectum, cancer, treatment.

\section{REFERÊNCIAS}

1. Martinez-Gonzalez MD; Takahashi T; Leon-Rodriguez E; Gamboa-Dominguez A; Lome C; Garcia-Blanco MC; et al. Case report of primary squamous carcinoma of the rectum. Rev Invest Clin 1996; 48(6): 453-6.

2. Audeau A; Han HW; Johnston MJ; Whitehead MW; Frizelle FA. Does human papilloma virus have a role in aquamous cell carcinoma of the colon and upper rectum? Eur J Surg Oncol 2002; 28(6): 657-60.

3. Frizelle FA; Hobday KS; Batts KP; Nelson H. Adenosquamous and squamous carcinoma of the colon and upper rectum: a clinical and histopathologic study. Dis Colon Rectum 2001; 44 (3): 341-6.

4. Agnostopoulos G; Sakorafas GH; Kostopoulos P; Grigoriadis K; Pavlakis G; Margantinis G; et al. Squamous cell carcinoma of the rectum: a case report and review of the literature. Eur J Cancer Care 2005; 14(1): 70-4.

5. Gelas T; Peyrat P; François Y; Gerard JP; Baulieux J; Gilly FN; et al. Primary squamous cell carcinoma of the rectum: report of six cases and review of the literature. Dis Colon Rectum 2002; 45(11): 1535-40.

6. Petrelli NJ; Valle AA; Weber TK; Rodriguez-Bigas M. Adenosquamous carcinoma of the colon and rectum. Dis Colon Rectum 1996; 39 (11): 1265-8.

7. Vezeridis MP; Herrera LO; Lopez JE; Ledesma EJ; Mittlemam A. Squamous cell carcinoma of the colon and rectum. Dis Colon Rectum 1983; 26: 188-91.

8. Rossi BM, Takagawa WT, Ferreira FO, Junior AS, Lopes A. Câncer de cólon, reto e ânus. In: Salvajoli JV, Anelli A, Chen MJ, Araújo BCB, editors. Radioquimioterapia em carcinoma de canal anal. 1a ed. São Paulo: Lemar e Tecmedd; 2004. p. 697-710. 
Rev bras Coloproct

Janeiro/Março, 2010
Carcinoma Espinocelular de Reto: Relato de Caso Juliana Magalhães Lopes e Cols.
Vol. 30

$\mathbf{N}^{\mathbf{0}} \mathbf{1}$
9. Lafreniere R; Ketcham A. Primary squamous carcinoma of the rectum: report of a case and review of the literature. Dis Colon Rectum 1985; 28: 967-72.
Endereço para correspondência:

\section{FLÁVIA BALSAMO}

Serviço de Coloproctologia do Hospital Heliópolis

Rua Cônego Xavier, 276

Vila Heliópolis - São Paulo, S.P.

CEP: 04231-030

Tel.: (11) 2274-7600 (ramal 244)

E-mail: flabal@uol.com.br 